\title{
TECCIENCIA
}

\section{Swimming pool heating systems: a review of applied models}

\section{Sistemas de climatización para piscinas: una revisión a los modelos de evaluación aplicados}

\author{
Silvio Alejandro Jiménez ${ }^{1 *}$, Victor Carrillo², Manuel Alejandro Alvarado Bettelli ${ }^{3}$. \\ 1*Universidad de la Salle,Bogotá, Colombia,sajimenezc@libertadores.edu.co \\ ${ }^{2}$ Universidad autónoma de Colombia,Bogotá, Colombia, vncarrilloa@libertadores.edu.co \\ ${ }^{3}$ Fundación Universitaria los libertadores, Bogotá, Colombia, ma.al.al.be@hotmail.com
}

\begin{abstract}
Swimming pool heating that is both efficient and ecological has become increasingly important to the development of new technologies and initiatives to protect the environment. This article, therefore, outlines previous research on the subject, acquired primarily from secondary sources and filtered based on criteria such as relevance, credibility, consistency, and applicability. Our goal is to provide an overview of the current literature and point out less-developed areas where research could be expanded. The results of the various studies suggest a widespread disagreement over calculating evaporation and make clear the need to generate integrative models that standardize this calculation.
\end{abstract}

Keywords: heating, swimming pools, modeling, verification.

\section{Resumen}

La climatización de piscinas de manera eficiente y ecológica aumenta en relevancia con el pasar del tiempo, debido al desarrollo de nuevas tecnologías e iniciativas de protección al medio ambiente. Por estas razones, este artículo describe investigaciones desarrolladas sobre el tema, adquiridas principalmente de fuentes secundarias y filtradas sobre criterios de selección sobre su relevancia, credibilidad, coherencia y aplicabilidad, para establecer un panorama sobre el estado del arte actual y sugerir la profundización de la investigación sobre las áreas que presenten menor desarrollo. Los resultados de los diferentes estudios sugieren una inconformidad generalizada sobre el cálculo de la evaporación y la necesidad por generar modelos integradores que estandaricen su cálculo.

Palabras clave: climatización, modelado, piscinas, verificación

\section{Introduction}

Although many countries enjoy climate conditions favorable to extensive swimming throughout the year, the vast majority of the world has only a few months per year to enjoy the recreational activity without the use of a heating system. In response to this problem, people often install roofs and combustion heating systems to procure comfortable temperatures in climates that would not naturally allow for swimming. This is achieved at the expense of two major items: the pool owner's budget and the environment.

*Corresponding Author.

E-mail: sajimenezc@libertadores.edu.co

Cellphone: (+57) 31282385562
In order to extend swimming seasons in countries with colder months and at the same time safeguard the financial interests of the owners, increasingly efficient systems have been developed. They integrate mechanisms that obtain energy through unconventional methods and thermoregulation techniques that reduce heat loss from the pool.

These methods are in accordance with the current global trend of environmental conservation and reduced fossil fuel consumption. Such research not only generates knowledge but also revises already-existing knowledge. This review article provides a glimpse of the current literature on How to cite: Jiménez, S.; Carrillo, V.; Alvarado, M., Swimming pool heating systems: a review of applied models, TECCIENCIA, Vol. 10 No. 19., 17-26, 2015, DOI: http:/dx.doi.org/10.18180/tecciencia.2015.19.4 
relevant pool heating research. It also includes an analysis of the most conclusive results in order to direct future research and correct possible failures.

The efficiency of a swimming pool heating system is a factor that allows the user to have an idea of the proportion of the energy utilized. Consequently, performance becomes an indicator of quality, and, therefore, a valid criterion for selecting a swimming pool. From the point of view of saving energy, heating the pool using renewable resources represents an interesting engineering challenge and is a target for constant research and investment of resources in the development of new technologies.

Research on the matter can be divided into three large groups, based on their contribution. First, improvements, if the research suggests adaptations to existing systems. Second, modeling, if they offer new analytical models that facilitate and/or better describe all relevant phenomena regarding the calculation and design of swimming pool heating systems. Third, verification, if they study and verify such models. Furthermore, the research can be categorized based on the object of study; namely, outdoor pools, indoor pools, or joint research (both indoor and outdoor).

\section{Analysis methodology and data collection}

The following questions were considered in our analysis: what studies have been carried out on pool heating? What gaps in knowledge currently exist? What are the research trends regarding pool heating? Subsequently, we searched the literature on tdr, proquest, ebscohost, ieee, jstor, redalyc and science direct. The searches were conducted using the following descriptors and their combinations: swimming pool heating, solar heating, hybrid systems, design, comparison, performance, energy savings, and analysis.

From the search results, we pre-selected 155 records using the following search criteria. A) relevance and usefulness of the title for the subject. B) credibility of the results of the study, according to the methodology used to obtain them. C) coherence and consistency of the summary. D) applicability of the results, and e) review objectives. Locating and obtaining the full text of these sources was done using the same databases, particularly science direct.

Now with the full-text sources in hand, a final selection was done by critically reading the 155 records and applying criteria of credibility, accuracy and relevance on the results. This process gave, as a result, the 68 academic studies that are analyzed in this paper. The selected papers primarily pertain to mathematical modeling, simulations, experiments and measurements on pool heating systems.

\section{Swimming pool heating systems}

\subsection{Improvements}

3.1.1. Indoor swimming pools

The study of heat pumps to dehumidify indoor pools has been a recurrent subject of research. Sun p. Et al. Developed a model to define the indoor pool heating system, based on energy balance. They also modeled the heat pump dehumidifier, disregarding the heat exchange between the refrigerant pipes and its environment, and the frost formation in the air-to-air heat exchanger in the winter. The model assumes one single temperature of condensation [1]

Chow et al. Researched the efficiency of a solar-assisted heat pump, through numerical simulation in trynsys [2]. Lazzarin r. Performed a thermodynamic and financial comparison of a compression heat pump, an absorption pump, a motor drive pump with heat recovery, and a combined system. The latter proved to be the most efficient [3]. Meanwhile johansson 1. And 1. Westerlund studied the mechanical heat pump and the open absorption system. The results demonstrated that the conventional ventilation technique requires more outside air. They also concluded that the energy demand increased with relatively higher humidity and that for lower air temperatures heat recovery systems are more useful [4].

Lazzarin r. And g. Longo presented an open cycle absorption system for chemical dehumidification. Comparisons were established between several systems. The results showed that simple ventilation needs $40 \%$ more power than a heat recovery system, while an electric heat pump and the internal combustion engine heat pump require $13 \%, 26 \%$, and $31 \%$ more power. The use of a chemical dehumidifier reduces the potential exhaust gas losses, but it also reduces the sensible heat recovered by the air-to-air heat exchanger, which reduces its efficiency [5].

Tagliafico et al. Analyzed the potential use of hydraulic solar-assisted heat pumps (w-sahp) for swimming pools, including data from all italian municipalities. They generated an equation for estimating energy savings. The system is capable of guaranteeing an annual pes (primary energy saving index) of over $35 \%$, in all locations analyzed. This is up to a maximum pes nearing $50 \%$ in towns with mild climates [6].

J. Noguera evaluates different heating alternatives for a municipal semi-olympic covered swimming pool for public use. Various technical-economic scenarios are proposed, starting from a combined system comprised of a geothermal installation, a solar installation, and a natural gas boiler for covering peak energy demand. The air conditioning was calculated using a simplified method - conducting heat 
through the walls of the building using the one-dimensional heat conduction equation for each wall and evaporating water using the bernier equation for indoor pools. Various configuration possibilities are offered for heating with solar panels. For systems supported by a natural gas boiler, and for systems supported by a geothermal heat pump, either independently or mixed with a condensing boiler or an airto-water heat pump. As for the support system, the study considers the implementation of either electric heating or of a condensing natural gas boiler, pellet boiler, biomass boiler, and waste boiler [7].

Trianti-stourna et al. Identified the technical, functional, and administrative obstacles for saving energy in sports centers. Meanwhile, they proposed practical and profitable solutions for improving energy efficiency and thermal and visual comfort in indoor pools throughout the year. The results of the simulations of various actions applied to pools have in common the fact that the use of natural gas as a heating fuel results in the biggest cost savings [8].

Ribeiro e. Et al. Presented a variety of approaches for controlling a heating system, along with the rue measurement to cover the pool at night and to reduce consumption during peak hours. Resulting in a reduction of the energy consumption and improvement of the eei (energy efficiency index). The use of an hvac system (heating, ventilation, air conditioning) controlled at $80 \%$ of wet-bulb temperature, improves the eei by seven $\mathrm{kgoe} / \mathrm{m}^{2} /$ year. Additionally, using an insulating cover increased the difference by 2.7 eei and reduced the rue impact by $11 \%$ [9]

Solar collector performance is evaluated in research by dang A. These collectors were to be installed in a school in northern india to heat a swimming pool, replete backup boiler. The results are obtained only via mathematical modeling, and support the use of collectors with a cover for pools [10].

\subsubsection{Outdoor pools}

Chan w. W. And lam j. C. Evaluated the thermal performance, energy savings, indirect emissions and economic feasibility of using heat pumps for outdoor hotel pools in subtropical climates [11]. The feasibility of using heat pumps for heating pools in south africa, calculating the cost of the lifecycle of a heating system with a heat pump, and comparing it to the expense of the lifecycle of a solar heating system, was studied by greyvenstein g. P. And meyer jp.

They calculated the average monthly losses of an exterior pool and performed correlations - the results were positive for almost all the cases studied [12].
Czarnecki j.t. suggest an efficient method for using solar energy for heating, principally with pool covers [13]. Cusido j.a. and puigdomenech j. Evaluate the performance of a lowcost solar heating system for outdoor pools [14]. Cunio l.n. and sproul a.b. investigate the theoretical and experimental performance of solar collectors for pool heating without glazing and at low flow rates. They observed that performance is not heavily penalized until the flow drops below $50 \mathrm{l} / \mathrm{min}$. Therefore, efficiency for $60 \mathrm{l} / \mathrm{min}$ is about $15 \%$ of that obtained for $140 \mathrm{l} / \mathrm{min}$ [15].

In alkhamis a. I. And sherif s. A, a solar heating system with single-glass flat-plate collectors was compared with a solar heating/cooling system [16]. In croy r., the operational performance of four solar-heated swimming pools in germany were analyzed [17].

Verkannah s. Proposes strategies for saving energy and reducing greenhouse gasses, selecting a sequence of heating for a pool based on usage time and other relevant parameters [18]. Similarly, yucra r. C. Analyzes and measures the equipment necessary for heating an outdoor swimming pool in puno, peru, and the production of its shw (sanitary hot water) [19].

Szeic g. And mcmonagle r.c. developed a model to simulate the changing flows of a pool during the summer swimming season in toronto. They noted that for the use of a removable night cover, an opaque cover is the most effective. Implementing vinyl walls in the pool was also considered to take advantage of direct solar radiation, but the results proved ineffective for achieving comfort. Furthermore, their simulations on the use of solar collectors demonstrated that an increase in water temperature could be maximized if a transparent cover were used at night [20].

\subsubsection{Mixed pools}

Št’astný et al. Studied the feasibility of using residual hot air from the engine room of a water park to get heat through a heat pump [21]. Gayo a. Carried out an energy audit of the semi-covered heated pool at the "josé caballero" sports center in alcobendas, madrid, spain. The project was divided into four parts. As a savings measure, the study considered replacing the pool's current heater, installing a thermal blanket, combining the thermal blanket with the heater, and installing solar panels for shw production.

The use of the heater with the thermal blanket suggested greater savings than the sum of the savings of each of the measures separately, due to the hot night air being reused [22]. Facão j. And oliveira a.c. analyzed a solar/gas hybrid system of micro-power generation and heating for a swimming pool complex and office space [23]. 
3.2. Modelling

3.2.1. Indoor pools

Brambley m. R. And wells s. E. Presented a detailed methodology for the estimation of energy needs in the pool heating process and the swimming space, aiming to save energy by adopting energy conservation strategies [24]. Tiwari g. N. And sharma s. B. Developed an analytical expression for the efficiency of a heating system made up of collectors, a pump, and a heat exchanger [25].

Asdrubali f. Calculated the flow of evaporation of water in indoor pools using experimental research under various temperature, relative humidity, and air speed conditions. By controlling these variables, the rates of water evaporation, obtained with the mathematical model suggested in this paper, were compared against those of hansen matisen, smith, and shah. Hansen matisen's model proved to be of the greatest concordance. Since these values have experimental validity, astdrubali promotes their use over smith's method; even though the coefficient $k$ evaluated in the equation for calculating the rate of evaporation has an error of approximately $10 \%$ representing $7 \%$ of the total heat lost [26].

Lu t. Et al. Have an approach for artificial neural networks that can predict the rate of water evaporation without information about the occupants, tested on a five-pool indoor hall in finland. They used two neural networks for the study of evaporation. Neural network a worked only with the rate of water evaporation as an input while neural network $b$ used both the rate of water evaporation and time as its variables. Both have a modifier - called 'exchange rate' for the rate of water evaporation (roc) and include, in a simplified way, possible changes in the mass of evaporation at different times. Predictions were made one and two steps ahead; the step-by-step prediction presented the smaller error. As for the error obtained by both networks, $b$ turned out to be the most accurate of the two.

For the differences between predictions made both during and outside of operation, they performed comparisons on neural network $b$ at different times of the day. The predictions that were one- and two-steps in advance were determined to have an average absolute error, out of operation, of 0.8978 and 1.378 respectively. Meanwhile, the same figures during the operation were found to be 2.58 and 3.9 [27].

Mančić m.v. et al. Presented a mathematical model to determine the energy demands of an indoor pool. They use the multi-zone structure trnsys model and consider the hvac of the pool room together with the shw. To calculate the water evaporation rate, they used a general mathematical representation, using correlations on dalton's equation as a starting point, to calculate the evaporation rate. The constants in the equation were chosen based on the comparison between the results of evaporation rates in unoccupied pools, using different correlations, against the measurements from a scale model of an asdruballi indoor swimming pool. A constant temperature per swimmer was assumed, and a simplified version of auer's equation was used to relate the maximum swimming pool area that a swimmer can occupy with the number of occupants and a load factor $\mathrm{f}$. The latter was determined using trnsys type 14 for daily and monthly changes [28].

Albarracin e. M. Et al. Put forward formulas for applying calculations and ensuring both comfort and health in a semiolympic swimming pool. To determine the rate of evaporation of water as a function of the number of swimmers, they used bernier's formula for evaporation flux, varying the number of visitors and keeping the number of spectators at 70 . From the results, it is evident that dehumidification by the heat pump is, in this case, better for the introduction of outside air because it has better control and efficiency [29].

Singh m. Et al. Did a transient analysis on a pool connected to a group of solar collectors in active mode. They took into account the following considerations. I) no stratification was produced in the pool water and the evaporation took place only when the pool was in use. Ii) the heat losses through connecting pipes were negligible. Iii) the collector panel was disengaged during hours of no sun. Iv) the pool was covered with a removable insulating cover when not in use. V) the losses in bottom heat were assumed steady. Most of these assumptions adversely affected the accuracy of the generated model and should be resolved in the future [30].

Delgado j.p. developed a dynamic simulation system to evaluate the thermal behavior of the pool basin of a heated pool. The simulation program trnsys was used as a basis. The method has been validated by comparing the obtained results with data recorded in real pools. The following standards were used as guidelines to determine variables relevant to pools and the environment around it. Nide (spanish acronym for regulations for recreation and sports installations), rite (spanish acronym for regulations of thermal installations in buildings), cte (spanish acronym for technical building code) and the rules on sanitary conditions in the region of murcia.

Delgado's model considered the activity of swimmers in the pools and was verified against four public swimming pools with registered and/or estimated annual consumption and with the same characteristics as those analyzed by the model. Excluding the contribution of the boilers, the calculation of the thermal energy and thermal stratification of the body of water must be solved in future research [31]. 
Dong y. Et al. Seek to simplify plc water temperate control for a heating system controlled by software. They present a fuzzy algorithm combined with the smith predictor compensator to control pool temperature and thereby solve delays and inertia problems in the pool, saving computing power. The simulation results are analyzed, and the smith fuzzy controller is implemented on the plc, attaining real control effects [32].

\subsubsection{Outdoor pools}

Govaer d. And zarmi y. Developed an analytical thermal model for open and closed swimming pool, studying annual values [33]. Muñoz n. Proposed the design of a pool heating system made up of a solar collector and a storage tank. He compared their efficiency against conventional systems. Losses in the reservoir and the walls of the pool were assumed to be negligible, and the overall coefficient of loss was calculated using the ashrae criteria. Stationary conditions were assumed for all parameters involved in each of the parts of the system: pool, accumulator tank, collector, and tubing to study the energy behavior of the collector [34].

Moreover, santos et. Al. Propose a hybrid structure that integrates a thermodynamic model for pools and artificial neural networks (ann). Anns receive climate information about the regions where the pool is installed. The variation of the city's ambient temperature was determined analytically and compared with meteorological values measured by "tutiempo, 2011" for the same day and location, showing that the ambient temperature values were calculated with a maximum variation of $2^{\circ} \mathrm{c}$. For validation, three processes were taken into account.

The first considered daily data collected throughout every month for each of the 25 cities that were considered in training. The second considered three new cities that were not present in the training set, comparing real values and those calculated by the neural network. And the third consisted in the evaluation of the capability of generalization of the neural networks for data corresponding to regional microclimates that were not inserted in the training set. Additionally, two simulations with changes in the pool volume conducted, without water replenishment, to represent human activity. This was done to evaluate the level of activity of the swimmers and the frequency in which they entered and exited the pool [34].

Del rio rico s. Presents the process of designing a pool heating system, along with a comsol simulation of the degree of homogenization of the temperature throughout the volume of water. Possible improvements in the infrastructure of the pool were also suggested. The flow and power of centrifugal pump of the filtration system were measured experimentally. The evolution of the power system was plotted with and without a thermal blanket. The energy demand of the pool was observed to reduce on average by $31 \%$ with the use of the blanket.

The comsol simulation is inadequately validated since it did not take swimmers into account, whereas the experimental measures taken did. Although a subject of study was taken for analysis in the investigation, the goal was not to improve any specific existing system [35].

Ahmad i. And khan n.a. analyze the gains and losses in outdoor pools using local weather data for their calculations, using transparent plastic sheet covers [36].

Govind and ms sodha presented an analysis of heat transfer processes in the solar heating of a pool under two analytical models, one for outdoor and one for a pool with a pvc cover. The theoretical and experimental time variation of solar intensity and ambient temperature, in victoria, australia, show a close correlation with an average error of less than $0.1^{\circ} \mathrm{c}$. In the case of the outdoor pool, the error is no greater than $0.2^{\circ} \mathrm{c}[37]$

Zsembinszki g. Et al simulate the thermal behavior of water in the presence and absence of a pcm (phase-change material) storage system and study the effects on pcm comfort conditions. Two methods of pcm use for heating are presented; the first using the heat in the side walls and bottom of the pool, and the second using an external heat exchanger with $\mathrm{pcm}$. The results showed the difference between temperature values of the registered and simulated pool at less than $0.2^{\circ} \mathrm{c}$, and a deviation of 0.009 .

Implementing a pcm storage system in an outdoor pool can cause an increase in water temperature of up to $2^{\circ} \mathrm{c}$, even for a limited number of days, and occurs during periods of adverse weather conditions such as low sunlight, low air temperatures, or high wind speed.

On the contrary, when the weather is good and the pool water is warm enough to reach a comfortable level, pcms have the effect of reducing its temperature by absorbing excess heat [38].

Similarly, nouanegue h.f. et al propose a numerical model for pools with an energy balance that considers the volume of makeup water from the pool and the number of swimmers per day. As for the validation of the model, its purpose is to define the value of the correlation coefficient for evaporation $(a, b)$ and the coefficient of the relation between evaporation and heat loss by convection (cv), simulated using the trnsys tool and taking $\mathrm{a}$ and $\mathrm{b}$ from different correlations in various literature, and cv from bowen's research [39]. In this research, optimal parameters $\mathrm{a}, \mathrm{b}$, and $\mathrm{cv}$ were noted to have 
an average difference of $4.3,20.8$, and $5.6 \%$, respectively [40].

Luminosu i. And de sabata a. Study the feasibility of an outdoor pool with showers, solar heaters, and classic heaters in the region of timişoara, romania. The authors propose an algorithm to determine the energy gains and losses of the pool, and evaluate, initially, the efficiency of a solar-heated outdoor swimming pool [41].

Haaf w. Et al develops and validates a model for outdoor pools with a minimum surface and depth of $100 \mathrm{~m}$ and 0.5 $\mathrm{m}$, respectively. The results showed that, overall, the model has an acceptable behavior within the range of 21 to $26^{\circ} \mathrm{c}$, with a maximum error of $1^{\circ} \mathrm{c}$, and is no longer useful for temperatures above $28^{\circ} \mathrm{c}$ [42].

Wooley j. Et al describe and validate a previously developed model, using meteorological data to accurately predict the temperature of a swimming pool, with a maximum error of $1.1^{\circ} \mathrm{c}$. To validate these calculations, they performed an experiment on a residential outdoor pool. Swimmers were not allowed to enter, no replenishment water was added, and the filter pump was set to run continuously at a constant flow rate.

The mean squared error of the prediction of pool temperature was estimated in comparison with the measured values of $0.4^{\circ} \mathrm{c}$, with the biggest discrepancy of only $1.1^{\circ} \mathrm{c}$. It should be noted that the methodology for describing the shading of the pool every hour is the only variable that is not derived from other published work nor directly measured with instrumentation. There are also no "correction factors" used to calibrate it. The results show that the model is very accurate [43].

Additionally, sharma s. Calculated heat loss from a pool at the national institute of technology rourkela by conducting a study on evaporation losses using matlab. To calculate evaporation losses, the antoine equation deriving from the clausius-clapeyron relation was used. It was observed that for a constant humidity, evaporation losses increase together with the increase in ambient temperature [44].

Rakopoulus c. D. And vazeos e. Introduced a theoretical model for various energy fluxes in an outdoor solar heated pool (covered and uncovered) to calculate the transfer of turbulent flows of heat energy and mass. To calculate the direct and diffuse solar radiation gained in the pool basin, the orgill and hollands iterative method was used. For convection losses, the forced convection coefficient was calculated using the von karman universal speed profile for turbulent atmospheric air flowing parallel to the surface.

In order to solve the difficulty of some integrations, they used approximate models. They also used corrections on some equations, obtained experimentally in other investigations. The evaporation loss was calculated by drawing an analogy between heat transfer and mass transfer. This was done by replacing the prandtl number with the schmidt number and using the properties of air for an average temperature of $15^{\circ} \mathrm{c}$. The use of a night cover was modeled and the comparison between the calculated heat loss and the experimentally measured heat loss showed disparities throughout the day, being reduced towards the end of the day [45].

\subsubsection{Mixed pools}

Govaer d. Employs the usability method to calculate the total usable energy from a solar-assisted system to heat a swimming pool for a monthly and annual period [46]. Yadav y. P. And tiwari g.n. performed a transient analytical study of an indoor and an outdoor swimming pool, both equipped with solar panels and exposed to severe cold weather. They considered a system both with and without a heat exchanger [47].

As for the verification of the model, the behavior of the pool was simulated for four days and compared with numerical calculations found in francey et al. [48]. They observed that for an indoor pool with removable insulation, the results mimicked those of francey et al. - there is a reduction in heat loss at night. Furthermore, the simulations show that the system with collectors is that which manages to achieve higher temperatures. They also demonstrated that, with each passing day, the peak daily temperature increases, yet it in a lower fraction than the previous day, until it stabilizes. Comparatively, the francey et al. Experiment, shows similar behavior but is normalized earlier.

Borge d. Et al. Present an exergy efficiency analysis of buildings with thermal solar systems for the production of sanitary hot water (shw) and heating and cooling support. Analysis of heating and cooling on the coefficients of exergetic efficiency suggests that solar cooling systems should be considered for places with low cooling demands [49].

Duomarco j. L. And magnou m. P. Generate and verify analytical models for calculating the solar heating system for open and closed swimming pools. The study was divided into seven stages, all performed on the same pool to determine the best way to make use, year-round, pools of similar size. On the criterion of the collector area, five methods are offered to estimate the right amount of collection.

The results demonstrated that implementing a hybrid dieselsolar system proved to be both efficient and economic, if a cover is used [50]. Also, fahmy f. H. Et al. Simulates the 
estimated energy requirement for a semi-covered swimming pool in the winter for a hotel in the city of hurghada [51].

\subsection{Verification \\ 3.3.1. Indoor pools}

Shah $\mathrm{m}$. M. Introduces two new correlations for predicting evaporation in occupied indoor pools: an analytical and an empirical, based on data obtained in carrier [52], biasin and krumme [53], heimann and rink, doering [54], and smith et al. [55]. The new empirical correlation gave the best result with an average deviation of $16.2 \%$ and most data within \pm $20 \%$ while the phenomenological correlation had an average deviation of $26.3 \%$. The carrier correlation gave an average deviation of $36.9 \%$, but its performance for large numbers of occupation was satisfactory. The biasin and krumme and smith et al. Correlations were erratic. Despite smith et al.'s correlation being found to be in agreement with their data, this was not the case against the results of others [56].

\subsubsection{Outdoor pools}

Ruiz e. And martinez p.j. mathematically model the thermic behavior of an outdoor pool and validate the results via experimental measurements, also evaluating the effect of solar system field size through the trnsys. The simulations demonstrated the deviation of the evaporation rate from the models of smith et al, ashrae [57], richter [58], iso tc 180 [59], rohwer [60], mcmillan [61] of 0.354, 1.33, 0.036, $0.108,0.782$, and 0.149 , respectively. We can conclude that the equation with the least deviation is richter's while that with the most deviation is ashrae's. Taking the corrected equations from ashrae and mcmillan, a comparison was made with the values measured experimentally. The evaporation rate deviation in ashrae $\mathrm{x} 0.5$ was 0.008 lower than richter while the deviation of memillian's equation $\mathrm{x}$ 1.78 delivered results similar to its original version [62].

Almanza r. And lara j. Put forward a methodology for calculating the energy requirements for heating a pool, obtaining the natural water temperature by the "regulal falsi" method [63]. Smith c.c. et al seek to solve the disparity between the theoretical and experimental values and the evaporation rate of water from a swimming pool, presenting mathematical arrangements. The measurements, for an indoor pool, proved to be $36 \%$ lower than those obtained using ashrae's equation [64].

Harrington c. Y modera m. Refine a previously developed model, validating it this time with an in-use pool. They deliver results about the hourly temperature of the pool according to local hourly meteorological conditions and external heat flows. For validation, the pacmet (pool air conditioner model evaluation tool) software confirmed an excellent thermal performance, displaying a mean quadratic error of $0.6^{\circ} \mathrm{c}$ with a maximum deviation of $1.6^{\circ} \mathrm{c}$, and for its linear regression a coefficient of determination of 0.993 [65]

Hahne and kubler generate and validate a model that describes the behavior of outdoor pools, with support from a trnsys 13.1 subroutine. They took correlations of evaporation loss from different literature and included them in the model. To validate the model, they studied the average variance between the measured and simulated temperatures.

They concluded that for pools with lower air speed, rowher was better, whereas for the opposite case richter was better. Indeed, they found that one of the pools had an average air speed 4.2 times greater than the other, establishing the importance of wind speed on the calculation of losses from evaporation and the lack of an integrative model for high and low air speeds.

Moreover, for the rowher equation they employed trnsys parameter identification routine to find the best constants and correct the simulated model. They found greater accordance, sacrificing the logic behind the effective absorption of sun energy since in the rowher equation it is 0.9 and in the trnsys subroutine 0.56 . With the original rowher equation, a standard variance of $0.51 \mathrm{k}$ was obtained. Moreover, after correcting the absorption with trnsys, it became 0.35 , from which the model can be concluded not to possess good transferability to other cases [66].

\subsubsection{Mixed}

Smith c. C. Et al. Presented an experiment to determine the rates of evaporation in swimming pools under four distinct conditions. The study was motivated by the inconsistency in the ashrae evaporation loss equation. Four evaporation measuring programs were performed on indoor and outdoor pools. The values of the ashrae evaporation equation were compared to values obtained with the corrected equation suggested in the study, obtained by mathematical modeling and verified via experiment.

Two methods were used to determine the rate of evaporation. The first was to measure the change in water level during an extended period, without mechanical inclusion or expulsion of water, whereas the second was to determine heat losses by evaporation using a balance of energy. The results suggest that the average Ashrae equation values for evaporation from covered pools are $26 \%$ greater than the values measured, while, for unoccupied covered pools, they are $74 \%$ of the value measured experimentally. 
They found that the water dragged with swimmers every time they exit and enter the pool, as well as the wind velocity in places where winds are changeable, make calculations of loss evaporation difficult. The results also show that indoor and outdoor pools without water movement, under similar control conditions, have similar evaporation rates [67].

\section{Conclusions}

There is a lack of a standard method for calculating losses in a pool, especially in terms of quantifying evaporation losses. Research should be conducted dedicated to generating models that calculate heat loss due to evaporation, with the aim of generating a standard model capable of delivering values closer to reality. The models should strive, above all, to solve evaporation losses in occupied outdoor and indoor pools, because on this matter researchers have not reached a consensus.

We suggest the creation of an experimentally corrected analytical model, measured in pools of different sizes and with different numbers of occupation, under low and high use margins (for the few or many waves produced by swimmers), and for various climate parameters.

The heat pump has been observed to be, in general, an efficient and economical option. Of particular note is the auxiliary heat generation by an air-to-water heat pump for low external air temperatures. Except for cases in which no financial investment whatsoever is desired, a hybrid system on a dedicated system is recommended.

Moreover, considering an auxiliary air-to-water heat generation pump as a first alternative is especially recommended. This mechanism allows the efficient delivery of heat with low cost and low difficulty of implementation, as long as environmental temperatures are low enough for heat recovery to be a viable alternative.

The use of a night cover represents considerable savings in consumption, although its contribution to savings is not restricted to night use only. All heated pools where the reduction of costs of heating is desired should have a cover to reduce evaporation losses.

Unfortunately, there is no well-defined standard of implementation for the material and its morphological characteristics, which is why further research is suggested. Although the cover is used at night, using the cover during hours of inactivity is recommended to reduce heat loss.

\section{References}

[1] P. Sun, J. Y. Wu, R. Z. Wang y Y. X. Xu, «Analysis of indoor environmental conditions and heat pump energy supply,» Energy and Buildings, vol. 43, $\mathrm{n}^{\circ}$ 5, p. 1071-1080, 2011.

[2] T. Chow, Y. Bai, K. Fong y Z. Lin, «Analysis of a solar assisted heat pump system for indoor swimming pool water and space heating,» Applied Energy, nº 100, p. 309-317, 2012.

[3] R. Lazzarin, «Alternative heating of a municipal swimming pool,» Revue Internationale du Froid, vol. 6, n 2, pp. 118-122, 1983

[4] L. Johansson y L. Westerlund, «Energy savings in indoor swimming-pools: comparison between different heat-recovery systems, , Applied Energy, $\mathrm{n}^{\circ}$ 70, pp. 281-303, 2001

[5] R. M. Lazzarin y G. A. Longot, «Comparison of heat recovery systems in public indoor swimming pools,» Applied Thermal Engineering, vol. 16, $\mathrm{n}^{\circ}$ 7, pp. 561-570, 1996.

[6] L. A. Tagliafico, «An approach to energy saving assessment of solar assisted heat pumps for swimming pool water heating,» Energy and Buildings, $\mathrm{n}^{\circ}$ 55, p. 833-840, 2012.

[7] S. Noguera, «Climatización de una piscina cubierta mediante la combinación de energía solar térmica, geotermia y caldera de apoyo de biomasa.,» Universidad de Barcelona, Universidad plitécnica de Catalunya, Barcelona, 2011.

[8] E. Trianti-Stourna, K. Spyropoulou, C. Theofylaktos, K. Droutsa, C. Balaras, M. Santamouris, D. Asimakopoulos, G. Lazaropoulou y N. Papanikolaou, «Energy conservation strategies for sports centers: Part B . Swimming pools,» Energy and Buildings, vol. 27, $\mathrm{n}^{\circ}$ 2, pp. 123-135, 1998.

[9] E. Ribeiro, H. M. Jorge y D. Quintela, «HVAC System Energy Optimization in Indoor Swimming Pools,» de Proceedings of the 2011 3rd International Youth Conference on Energetics (IYCE) , Leiria, 2011.

[10] A. Dang, «A parametric study of swimming pool heating,» Energy Conversion and management, vol. $26, \mathrm{n}^{\circ} 1$, pp. 27-31, 1986.

[11] W. W. Chan y J. C. Lam, «Energy-saving supporting tourism sustainability: A case study of hotel swimming pool heat pump,» Journal of Sustainable Tourism, vol. 11, n 1, pp. 74-83, 2003

[12] G. P. Greyvenstein y J. P. Meyer, «The viability of heat pumps for the heating of swimming pools in South Africa,» Energy, vol. 16, $\mathrm{n}^{\mathrm{o}}$ 7, pp. 1031-1037, 1991

[13] J. T. Czarnecki, «A Method of Heating Swimming Pools by Solar Energy,» Solar Energy, vol. 7, n 1, pp. 3-7, 1963.

[14] J. A. Cusido y J. Puigdomenech, «An experimental solar system for swimming pool heating in Mediterranean climates,» Solar\& Wind Technology, vol. 3, n 2, pp. 141-145, 1986.

[15] L. Cunio y A. Sproul, «Performance characterisation and energy savings of uncovered swimming pool solar collectors under reduced flow rate conditions,,$>$ Solar Energy, no 86, p. 15111517, 2012.

[16] A. I. Alkhamist y S. A. Sheriff, «Performance analysis of a solar-assisted swimming pool heating system,» Energy, vol. 17, $\mathrm{n}^{\mathrm{o}} 12$, pp. 1165-1172, 1992.

[17] R. Croy, «Development of low-cost solar plants for swimming pool water heating,» de Clean and Safe Energy Forever, Hilden, International Solar Energy Society, 1990, pp. 806-810.

[18] S. Verkannah, «Reducing fuel consumption and $\mathrm{CO} 2$ emission by properly selecting the parameters for pool heating,» de AFRICON 2002 Conference, George, 2002. 
[19] R. C. Yucra, «Estudio para la climatización de la piscina y la produccion de agua caliente sanitaria acs con energia solar de la UNAP,》 de IV Conferencia Latino Americana de Energía Solar (IV ISES CLA) y XVII Simposio Peruano de Energía Solar (XVII - SPES), Cusco, 2010

[20] G. Szeic y R. C. McMonagle, «The heat balance of urban swimming pools,» Solar Energy, vol. 30, n 3, pp. 247-259, 1983.

[21] B. Št’astný, K. Slavíčková y B. Ježková, «Energy saving possibilities for swimming pools,» International Journal of Engineering Sciences and Research Technology, vol. 7, $\mathrm{n}^{\mathrm{o}} 3$, pp 768-774, 2014.

[22] A. Gayo, Auditoría energética en una piscina climatizada Universidad Pontificia Comillas, 2009.

[23] J. Facão y A. C. Oliveira, «Analysis of a micro-cogeneration system using hybrid solar/gas collectors, $\gg$ International Journal of Low Carbon Technologies, vol. 4, nº 1, pp. 285-297, 2006.

[24] M. R. Brambley y S. E. Wells, «Energy-conservation measures for indoor swimming pools,» Energy, vol. 8, n 6 , pp. 403-418, 1983.

[25] G. N. Tiwari y S. B. Sharma, «Design parameters for indoor swimming-pool heating using solar energy,» Energy, vol. 16, $\mathrm{n}^{\circ}$ 6, pp. 971-975, 1991.

[26] F. Asdrubali, «A scale model to evaluate water evaporation from indoor swimming pools,» Energy and Buildings, $\mathrm{n}^{\circ} 41, \mathrm{p}$. 311-319, 2009

[27] T. Lu, X. Lü y M. Viljanen, «Prediction of water evaporation

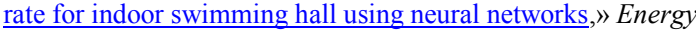
and Buildings , $\mathrm{n}^{\circ}$ 81, p. 268-280, 2014.

[28] M. V. Mančić, D. S. Živković, P. M. Milosavljević y T. M. N., «Mathematical modelling and simulation of the thermal performance of a solar heated indoor swimming pool,» Thermal Science, vol. 18, nº 3, pp. 999-1010, 2014.

[29] E. M. Albarracín, J. Sanabria y A. Maíllo, «Ahorro de energía en piscinas cubiertas,» El instalador, $n^{\circ}$ 441, pp. 16-37, 2007.

[30] M. Singh, G. N. Tiwari y Y. P. Yadav, «Solar energy utilization for heating of indoor swimming poolhttp://www.sciencedirect.com/science/article/pii/019689048 9900277,» Energy Convers. Mgmt , vol. 29, n 4, pp. 239-244, 1989.

[31] J. P. Delgado, Modelado dinámico de una piscina climatizada asistida con energía solar. Universidad Politécnica de Cartagena, 2013.

[32] Y. Dong, H. Yonghong y X. Gaohong, «Design of Indoor Swimming Pool Water Temperature Control System Based on Fuzzy Controller and Smith Predictor,» de 2010 International Conference on Intelligent and Advanced Systems (ICIAS), Kuala Lumpur, 2010.

[33] D. Govaer y Y. Zarmi, «Analytical evaluation of direct solar heating of swimming pools, , Solar Energy, vol. 27, $\mathrm{n}^{\circ} 6$, pp 529-533, 1981.

[34] N. Muñoz, «Obtención de agua caliente para piscinas utilizando colectores solares de placa plana operando por termosifón.» Universidad Tecnológica de Pereira, 2010.

[35] E. T. Santos, L. E. Zárate y E. M. D. Pereira, «Hybrid thermal model for swimming pools based on artificial neural networks,, Expert Systems with Applications, $\mathrm{n}^{\circ}$ 40, p. 3106-3120, 2013.

[36] S. D. R. Rico, «Diseño del sistema de calefacción de la piscina de la UPB, campus laureles,» Universidad Pontificia Bolivariana, 2010.

[37] I. Ahmad y N. A. Khan, «Solar swimming pool heating in Pakistan,» de Proceedings of ISES World Congress 2007 (Vol. I - Vol. V), Springer Berlin Heidelberg, 2009, pp. 2033-2037.
[38] Govind y M. Sodha, «Thermal model of solar swimming pools,» Energy Convers. Mgmt, vol. 23, nº 3, pp. 171-175, 1983.

[39] G. Zsembinszki, M. M. Farid y L. F. Cabeza, «Analysis of implementing phase change materials in open-air swimming pools,» Solar Energy , no 86, p. 567-577, 2012.

[40] I. Bowen, «The ratio of heat losses by conduction and by evaporation from any water surface,» Physical review, vol. 27, pp. 779-787, 1926 .

[41] H. F. Nouanegue, S. Sansregret, B. LeLostec y A. Daoud, «Energy model validation of heated outdoor swimming pools in cold weather,» de Proceedings of Building Simulation 2011:12th Conference of International Building Performance Simulation Association, Sydney, 2011.

[42] I. Luminosu y A. DeSabata, «Feasibility of a Solar Swimming Pool in the Western Part of Romania,» de 8th IEEE International Symposium on Applied Computational Intelligence and Informatics, Timisoara, 2013.

[43] W. Haaf, U. Luboschik y B. Tesche, «Solar swimming pool heating: description of a validated model,» Solar Energy, vol. 53, nº 1, pp. 41-46, 1994

[44] J. Woolley, C. Harrington y M. Modera, «Swimming pools as heat sinks for air conditioners: Model design and experimental validation for natural thermal behavior of the pool,» Building and Environment, $\mathrm{n}^{\circ}$ 46, pp. 187-195, 2011.

[45] S. Sharma, Calculation of heat losses from nit-Rourkela's swimming pool and a study on evaporative losses using MATLAB. National Institute of Technology, Rourkela, 2011.

[46] C. Rakopoulos y E. Vazeos, "A model of the energy fluxes in a solar heated swimming poll and its experimental validation,, Energy convers Mgmt, vol. 27, $\mathrm{n}^{\circ}$ 2, pp. 189-195, 1987.

[47] D. Govaer, «Determining the solar heating of swimming pools by the utilizability method,» Solar Energy, vol. 32, $n^{\circ} 5$, pp. 667-669, 1984.

[48] Y. P. Yadav y G. N. Tiwari, «Analytical model of solar swimming pool: transient approach,» Energy Convers. Mgmt, vol. $27, \mathrm{n}^{\circ} 1$, pp. 49-54, 1987.

[49] J. L. A. Francey, P. Golding y R. Clarke, «Low- cost solar heating of community pools using pool covers,» Solar Energy, vol. $25, \mathrm{n}^{\circ}$ 5,pp 407-416, 1980 .

[50] D. Borge, A. Colmenar, M. Castro, S. Martín y E. Sancristobal, «Exergy efficiency analysis in buildings climatized with $\mathrm{LiCl}_{-}$ $\mathrm{H} 2 \mathrm{O}$ solar cooling systems that use swimming pools as heat sinks,» Energy and Buildings, n ${ }^{\circ}$ 43, pp. 3161-3172, 2011

[51] J. L. Duomarco y M. Pérez, «Solar heating of swimming pools,» de Ninth International IBPSA Conference, Montréal, 2005.

[52] F. H. Fahmy, H. M. Farghally y N. M. Ahmed, «Swimming Pool System Based on Geothermal Energy in Egypt,» Journal of Next Generation Information Technology (JNIT), vol. 5, $\mathrm{n}^{\circ}$ 1, pp. $27-40,2014$

[53] W. Carrier, «The temperature of evaporation,» ASHVE Trans, vol. 24, pp. 25-50, 1918.

[54] K. Biasin y W. Krumme, «Die Wasserverdunstung in einem Innenschwimmbad,» Electrowaerme International, vol. 32, $\mathrm{n}^{\circ}$ A3, p. A115-A129, 1974.

[55] E. Doering, «Zur Auslegung von Luftungsanlagen fur Hallenschwimmbader,» $H L H$, vol. 30, n $^{\circ}$ 6, p. 211-216, 1979.

[56] C. Smith, G. Lof y R. Jones, «Rates of evaporation from swimming pools in active use,» ASHRAE Trans, vol. 104, $\mathrm{n}^{\circ}$ 1A, pp. 514-523, 1999.

[57] M. M. Shah, «Prediction of evaporation from occupied indoor swimming pools,, Energy and Buildings, $\mathrm{n}^{\circ} 35$, p. 707-713, 2003. 


\section{TECCIENCIA}

[58] ASHRAE, ASHRAE Applications Handbook, 2003.

[59] D. Richter, «Temperatur- und Wa"rmehaushalt des thermisch belasteten Stechlin- und Nehmitzsees,» de Abhandlung des Meteorologischen, Berlin, Akademie-Verlag, 1979, p. 123.

[60] 1. ISO/TC 180/SC 4 N 140, «Solar Energy - Heating Systems for Swimming Pools - Design and Installation.,» 1995.

[61] C. Rohwer, Evaporation from Free Water Surfaces., United States, Department of Agriculture: Technical Bulletin No. 271., 1931.

[62] W. McMillan, «Heat dispersal,» de Lake Trawsfynydd cooling studies In: Symposium on Freshwater Biology and Electrical Power Generation, Part 1, 1971, pp. 41-80.

[63] E. Ruiz y P. J. Martínez, «Analysis of an open-air swimming pool solar heating system by using an experimentally validated TRNSYS model,» Solar Energy, nº 84, pp. 116-123, 2010.
[64] R. Almanza y J. Lara, «Energy requirements for a swimming pool through a water-atmosphere energy balance,» Solar Energy, vol. 53, no 1, pp. 37-39, 1994.

[65] C. C. Smith, G. Lof y R. Jones, «Measurement and analysis of evaporation from an inactive outdoor swimming pool,» Solar Energy, vol. 53, n 1, pp. 3-7, 1994.

[66] C. Harrington y M. Modera, «Swimming pools as heat sinks for air conditioners: California feasibility analysis,, Energy and Buildings, $\mathrm{n}^{\circ}$ 59, p. 252-264, 2013.

[67] E. Hahne y R. Kubler, «Monitoring and simulation of the thermal performance of a solar heated outdoor swimming polls,» Solar Energy, vol. 53, nº 1, pp. 9-19, 1994. 